\title{
The 2009-2010 Arctic polar stratospheric cloud season: a CALIPSO perspective
}

\author{
M. C. Pitts ${ }^{1}$, L. R. Poole ${ }^{2}$, A. Dörnbrack ${ }^{3}$, and L. W. Thomason ${ }^{1}$ \\ ${ }^{1}$ NASA Langley Research Center, Hampton, Virginia, 23681, USA \\ ${ }^{2}$ Science Systems and Applications, Incorporated, Hampton, Virginia, 23666, USA \\ ${ }^{3}$ DLR, Institut für Physik der Atmosphäre, 82230 Oberpfaffenhofen, Germany
}

Received: 17 August 2010 - Published in Atmos. Chem. Phys. Discuss.: 18 October 2010

Revised: 28 January 2011 - Accepted: 25 February 2011 - Published: 10 March 2011

\begin{abstract}
Spaceborne lidar measurements from CALIPSO (Cloud-Aerosol Lidar and Infrared Pathfinder Satellite Observations) are used to provide a vortex-wide perspective of the 2009-2010 Arctic PSC (polar stratospheric cloud) season to complement more focused measurements from the European Union RECONCILE (reconciliation of essential process parameters for an enhanced predictability of Arctic stratospheric ozone loss and its climate interactions) field campaign. The 2009-2010 Arctic winter was unusually cold at stratospheric levels from mid-December 2009 until the end of January 2010, and was one of only a few winters from the past fifty-two years with synoptic-scale regions of temperatures below the frost point. More PSCs were observed by CALIPSO during the 2009-2010 Arctic winter than in the previous three Arctic seasons combined. In particular, there were significantly more observations of high number density NAT (nitric acid trihydrate) mixtures (referred to as Mix 2-enh) and ice PSCs. We found that the 2009-2010 season could roughly be divided into four periods with distinctly different PSC optical characteristics. The early season (1530 December 2009) was characterized by patchy, tenuous PSCs, primarily low number density liquid/NAT mixtures. No ice clouds were observed by CALIPSO during this early phase, suggesting that these early season NAT clouds were formed through a non-ice nucleation mechanism. The second phase of the season (31 December 2009-14 January 2010) was characterized by frequent mountain wave ice clouds that nucleated widespread NAT particles throughout the vortex, including Mix 2-enh. The third phase of the season (1521 January 2010) was characterized by synoptic-scale temperatures below the frost point which led to a rare outbreak
\end{abstract}

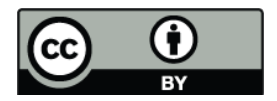

Correspondence to: M. C. Pitts (michael.c.pitts@nasa.gov) of widespread ice clouds. The fourth phase of the season (22-28 January) was characterized by a major stratospheric warming that distorted the vortex, displacing the cold pool from the vortex center. This final phase was dominated by STS (supercooled ternary solution) PSCs, although NAT particles may have been present in low number densities, but were masked by the more abundant STS droplets at colder temperatures. We also found distinct variations in the relative proportion of PSCs in each composition class with altitude over the course of the 2009-2010 Arctic season. Lower number density liquid/NAT mixtures were most frequently observed in the lower altitude regions of the clouds (below $\sim 18-20 \mathrm{~km}$ ), which is consistent with CALIPSO observations in the Antarctic. Higher number density liquid/NAT mixtures, especially Mix 2-enh, were most frequently observed at altitudes above $18-20 \mathrm{~km}$, primarily downstream of wave ice clouds. This pattern is consistent with the conceptual model whereby low number density, large NAT particles are precipitated from higher number density NAT clouds (i.e. mother clouds) that are nucleated downstream of mountain wave ice clouds.

\section{Introduction}

In spite of more than two decades of research, a detailed understanding of the processes leading to polar ozone depletion has not yet fully emerged. The role of polar stratospheric clouds (PSCs) in catalyzing heterogeneous chemical reactions that activate ozone-depleting halogens has become well established, but there are still open questions with regard to the formation of solid PSC particles, especially nitric acid trihydrate, NAT (e.g., Lowe and MacKenzie, 2008). These remaining uncertainties limit our ability to accurately represent

Published by Copernicus Publications on behalf of the European Geosciences Union. 
the ozone depletion processes in global climate models and call into question the capability of these models to predict the evolution of the ozone layer in a future stratosphere whose composition differs from the current state. This is of particular concern in the Arctic, where winter temperatures hover near the PSC formation threshold and, hence, future stratospheric cooling could lead to enhanced cloud formation and substantially greater ozone losses (WMO, 2007).

The general climatology of Arctic PSCs, such as their large interannual variability and asymmetric longitudinal distribution, has primarily been established through analyses of long-term data records from the Stratospheric Aerosol Measurement (SAM) II (1978-1993) and Polar Ozone and Aerosol Measurement (POAM) II/III (1996-2006) solar occultation satellite instruments (e.g. Poole and Pitts, 1994; Fromm et al., 2003). While extremely valuable, these historical occultation data sets provide only limited information on PSC composition and, due to significant sampling limitations, their climatologies are not necessarily representative of the polar regions as a whole (Pitts et al., 2007). Ground-based and airborne lidars have also contributed significantly to our understanding of Arctic PSC occurrence and composition, but these datasets are limited in spatial coverage and are strongly influenced by local meteorology. For instance, ice PSCs have been observed frequently by lidar near the Scandinavian mountains (e.g. Dörnbrack et al, 2002; Reichardt et al., 2004; Blum et al., 2005) and over Sodankylä, Finland (Müller et al., 2001), but only under exceptional meteorological conditions over $\mathrm{Ny}$ Alesund (Maturilli and Dörnbrack, 2006; Massoli et al., 2006) and Greenland (di Sarra et al., 2002; Buss et al., 2004). A more complete picture of PSC morphology and composition on vortex-wide scales is now being provided by spaceborne lidar measurements from Cloud-Aerosol Lidar and Infrared Pathfinder Satellite Observations (CALIPSO) (Winker et al., 2007, 2009) and passive infrared measurements from MIPAS (Michelson Interferometer for Passive Atmospheric Sounding) on Envisat (e.g. Höpfner et al., 2006, 2009).

The European Union has also implemented the new fouryear research project RECONCILE (reconciliation of essential process parameters for an enhanced predictability of Arctic stratospheric ozone loss and its climate interactions) for more comprehensive and detailed investigations of key processes governing Arctic ozone depletion. A vital component of RECONCILE is an intensive field campaign of coordinated aircraft, balloon, and ground-based measurements related to PSCs and ozone chemistry that was conducted in the Arctic during January-March 2010 (von Hobe et al., 2010). The aircraft campaign was based in Kiruna, Sweden where the M55 Geophysica high-altitude research aircraft (Stefanutti et al., 1999) conducted a series of science flights carrying a full suite of in situ and remote particle and gas-phase constituent sensors. The flight campaign was implemented in two phases, with eight flights in the first phase from 17-28 January 2010 and four flights in the second phase from 27 February-5 March 2010. The RECONCILE Match balloon campaign took place in parallel with the aircraft campaign with more than 300 sondes launched from 26 stations across the Arctic.

Five flights during the first phase of the RECONCILE aircraft campaign specifically targeted PSC measurements. The in situ particle instruments provide information on PSC particle size, number densities, and $\mathrm{HNO}_{3}$ content, while the remote sensors provide information on the vertical and spatial extent of the clouds along the Geophysica flight track. Although these aircraft measurements are invaluable for detailed studies of polar processes, they are by nature limited both temporally (spanning a ten-day period) and spatially (localized along Geophysica flight tracks, which themselves were limited by the range of the aircraft and airspace constraints). On the other hand, the spaceborne CALIPSO lidar measurements provide a view of PSC properties on large spatial scales covering much of the polar region and spanning the entire winter, complementing the more focused Geophysica and balloon measurements from RECONCILE. Hence, the overall goal of this paper is to use spaceborne lidar measurements from CALIPSO to examine the evolution of PSCs during the 2009-2010 Arctic winter on vortex-wide scales and provide context to the more focused measurements obtained during the RECONCILE campaign. In Sect. 2, we briefly describe the CALIPSO PSC detection and composition discrimination algorithm and provide an update on the optical characteristics of PSCs observed by CALIPSO from 2006-2010. In Sect. 3, we describe the evolution of the polar vortex during the 2009-2010 Arctic winter and put this season into historical context from a meteorological perspective using European Centre for Medium-Range Weather Forecasts (ECMWF) and National Centers for Environmental Prediction/National Center for Atmospheric Research (NCEP/NCAR) Reanalyses datasets. In Sect. 4, we examine the four-year CALIPSO Arctic PSC record to show how this winter compares with the previous three Arctic winters in terms of PSC characteristics. In Sect. 5, we divide the 2009-2010 winter into four periods with distinctly different PSC optical characteristics and then analyze each of these periods in detail to illustrate how PSC composition evolved during the winter. The summary and conclusions are provided in Sect. 6.

\section{CALIPSO PSC detection and composition classification}

The CALIPSO satellite was launched in April 2006 and is a component of the A-train satellite constellation (Stephens et al., 2002). CALIPSO has an orbit inclination of $98.2^{\circ}$ which provides extensive daily measurement coverage over the polar regions of both hemispheres up to $82^{\circ}$ in latitude. The primary instrument on CALIPSO is a lidar (CALIOP, or CloudAerosol Lidar with Orthogonal Polarization) that measures 
backscatter at wavelengths of $1064 \mathrm{~nm}$ and $532 \mathrm{~nm}$, with the 532-nm signal separated into orthogonal polarization components parallel and perpendicular to the polarization plane of the outgoing laser beam. A description of CALIOP and its on-orbit performance can be found in Hunt et al. (2009), and details on calibration of the CALIOP data are provided by Powell et al. (2009).

CALIOP has proven to be an excellent system for observing PSCs (Pitts et al., 2007, 2009, hereafter referred to as P09). The second-generation CALIPSO PSC algorithm, described in detail in P09, detects clouds using both the CALIOP 532-nm scattering ratio $\left(R_{532}\right.$, the ratio of total to molecular backscatter, e.g., Cairo et al., 1999) and the 532-nm perpendicular backscatter coefficient in a successive horizontal averaging procedure that enhances the detection of tenuous PSCs. The algorithm also includes a scheme for classifying PSCs by composition based on the measured CALIOP aerosol depolarization ratio $\left(\delta_{\text {aerosol }}\right.$, the ratio of perpendicular to parallel components of aerosol backscatter, e.g., Cairo et al., 1999) and inverse scattering ratio $\left(1 / R_{532}\right)$. P09 defined four CALIPSO PSC composition classes: supercooled ternary solution (STS), water ice, and two classes (Mix 1 and Mix 2) of liquid/NAT mixtures. Mix 1 denotes mixtures with very low NAT number densities (from about $3 \times 10^{-4} \mathrm{~cm}^{-3}$ - the inferred CALIOP NAT sensitivity threshold - to $10^{-3} \mathrm{~cm}^{-3}$ ), while Mix 2 denotes mixtures with higher $\left(>10^{-3} \mathrm{~cm}^{-3}\right)$ NAT number densities. As noted in P09, the STS class may also include low number densities of NAT particles whose optical signature is masked by the more numerous liquid droplets at cold temperatures. At the date of this writing, CALIPSO has produced a PSC dataset covering four winters in both the Arctic and Antarctic. Figure 1 shows a composite 2-D histogram of these observations (totalling approximately 96 million 5-km horizontal by 180 $\mathrm{m}$ vertical cloud "pixels") in the $\delta_{\text {aerosol }}$ vs. $1 / R_{532}$ coordinate system, with the solid black lines denoting the boundaries of the four PSC composition domains defined by P09. The histogram bin size is $0.02 \times 0.02$ and the color scale indicates the total number of cloud observations falling within each bin.

Since P09, CALIPSO has produced three additional winters of PSC observations that highlight two additional interesting PSC optical features that may be important in advancing our understanding of NAT formation mechanisms. The first of these is the relatively larger number of observations of Mix 2 PSCs with values of $1 / R_{532}<0.5$ and $\delta_{\text {aerosol }}>0.1$ (denoted by the dashed box in Fig. 1). This subset of data is consistent with mixtures having sufficiently high NAT number densities $\left(>0.1 \mathrm{~cm}^{-3}\right)$ and volumes $\left(>0.5 \mu \mathrm{m}^{3} \mathrm{~cm}^{-3}\right)$ that their presence is not masked by the more numerous STS droplets at temperatures well below $T_{\mathrm{NAT}}$, the existence temperature for NAT (Hansen and Mauersberger, 1988). These characteristics are similar to the so-called Type 1a-enhanced PSCs first identified by Tsias et al. (1999) in airborne lidar data taken near Spitsbergen; hence, we will refer herein to

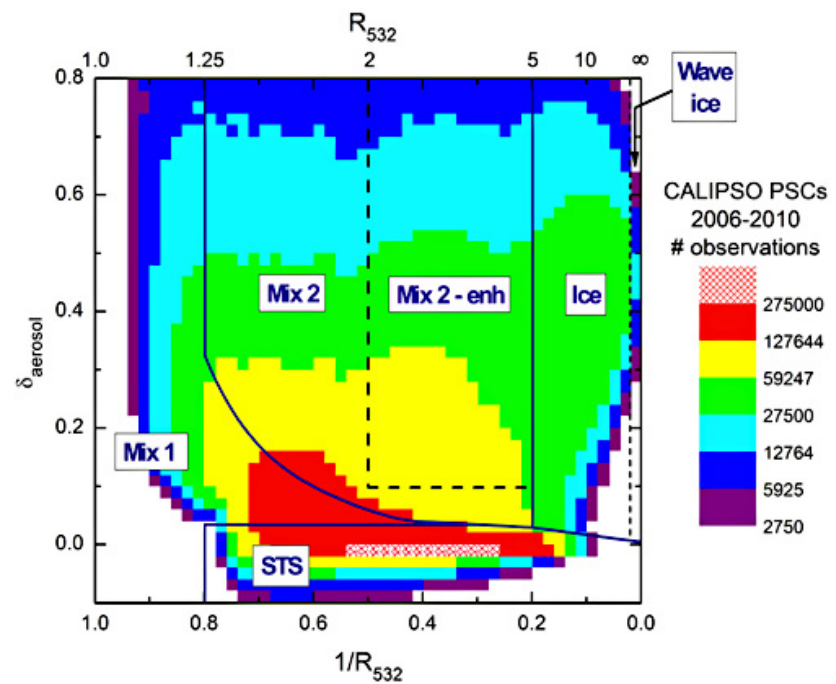

Fig. 1. Composite 2-D histogram of all CALIPSO PSC observations from $2006-2010$ in the $\delta_{\text {aerosol }}$ vs. $1 / R_{532}$ coordinate system, with the solid black lines denoting the boundaries of the four PSC composition domains defined by P09. The histogram bin size is $0.02 \times 0.02$ and the color scale indicates the total number of cloud observations falling within each bin. The domains of two new composition sub-classes, Mix 2-enh and wave ice, are denoted by dashed boxes.

this subset of CALIPSO data as Mix 2 enhanced (Mix 2enh) PSCs and separate them from those data lying within the rest of the Mix 2 domain. Secondly, we have found that intense mountain-wave induced PSCs can be distinguished as a subset of CALIPSO ice PSCs through their distinct optical signature in $R_{532}$ and lidar color ratio (the ratio of 1064-nm to 532-nm aerosol backscatter coefficients). In general, lidar color ratio is an indicator of particle size; cirrus and tropospheric clouds have color ratios around 1, indicating large particles, while smaller aerosol particles have lower color ratios (Liu et al. 2004). We do not use the color ratio in an absolute sense in our PSC algorithm because of calibration issues and the generally low signal-to-noise (SNR) of 1064-nm CALIOP data in the stratosphere (Hunt et al., 2009). However, an abrupt change in color ratio occurs for ice PSCs with very large scattering ratios (where the 1064-nm data are more reliable), which we feel is a clear signature of mountain wave PSCs. Figure 2 is a 2-D histogram of color ratio vs. $1 / R_{532}$ (with a bin size of $0.05 \times 0.02$ ) for CALIPSO ice PSC observations $\left(1 / R_{532}<0.2\right)$ from June 2006 to March 2010. Over most of the ice PSC domain, the maximum number of observations occurs at color ratios from $0.75-1.0$, indicating large particles. But for ice PSCs with $1 / R_{532}<0.02$, the maximum in the number of observations shifts abruptly to color ratios of $0.25-0.35$, which is consistent with mountain wave PSCs having high ice particle number densities ( $\sim 100 \%$ ice activation from the background aerosol) but relatively small particles $(1-1.5 \mu \mathrm{m}$ radius, e.g., Fueglistaler et 


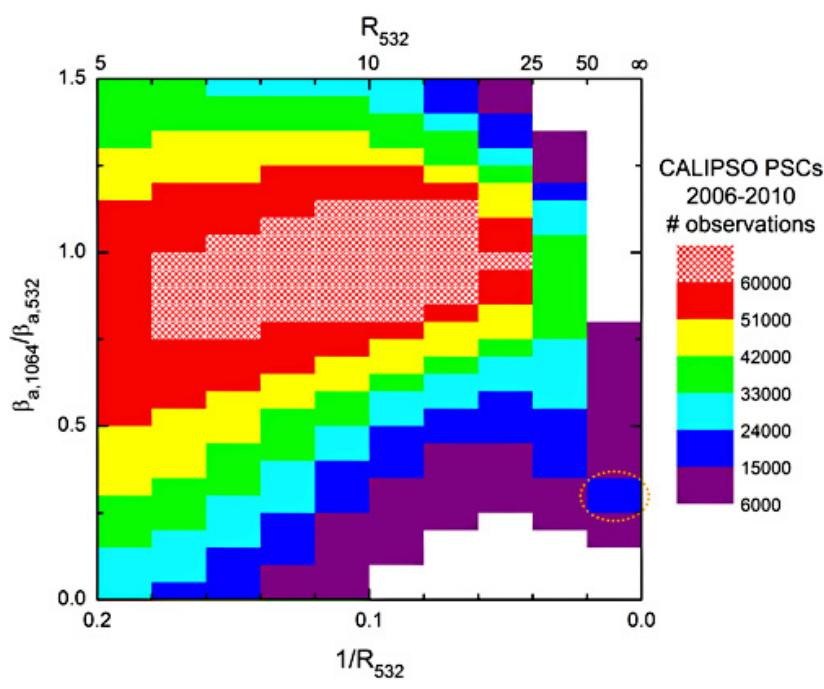

Fig. 2. Composite 2-D histogram of lidar color ratio $\left(\beta_{\mathrm{a}, 1064} / \beta_{\mathrm{a}, 532}\right)$ vs. $1 / R_{532}$ (with a bin size of $0.05 \times 0.02$ ) for CALIPSO PSC observations with $1 / R_{532}<0.2$ from June 2006 to March 2010. Dashed red circle indicates abrupt shift in color ratio associated with wave clouds at $1 / R_{532}<0.02$.

al., 2003; Carslaw et al., 1998). Therefore, we will interpret CALIPSO ice cloud observations with $1 / R_{532}<0.02$ as mountain wave PSCs. Note that the CALIPSO wave-ice PSC class is not all-inclusive; some additional CALIPSO ice PSC observations are likely associated with mountain waves, but do not meet our strict $\left(1 / R_{532}<0.02\right)$ wave-ice identification criterion, e.g. observations immediately upwind or downwind of the location of peak backscatter.

Figure 3 shows the composition breakdown of PSCs observed by CALIPSO in the Arctic and Antarctic. The percentages are averages over four seasons in each hemisphere, and the minimum and maximum percentages in any one season are the numbers in brackets. There are several notable differences between the hemispheres: (1) there are 25 times more CALIPSO PSC observations in the Antarctic; (2) yearto-year variability in PSC composition is much higher in the Arctic; (3) the fraction of ice PSCs is a factor of four smaller in the Arctic; (4) the fraction of Mix 2-enh PSCs in the Arctic $(13 \%)$ is about half the fraction observed in the Antarctic, but is much larger than the 1-4\% of Type 1a-enh clouds reported in the Ny Alesund ground-based lidar PSC climatology (Biele et al., 2001; Massoli et al., 2006).

\section{The 2009-2010 Arctic winter}

The 2009-2010 Arctic winter was unusually cold at stratospheric levels during the six-week period from midDecember 2009 until the end of January 2010. Cooling of the Arctic polar vortex generally tracked the 20-yr ECMWF climatological mean through late November 2009, when the
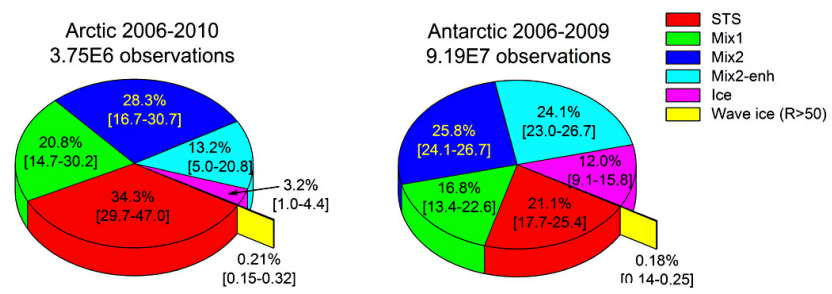

Fig. 3. Composition breakdown of PSCs observed by CALIPSO in the Arctic and Antarctic during 2006-2010. The percentages are averages over four seasons in each hemisphere, and the minimum and maximum percentages in any one season are indicated by the numbers in brackets.

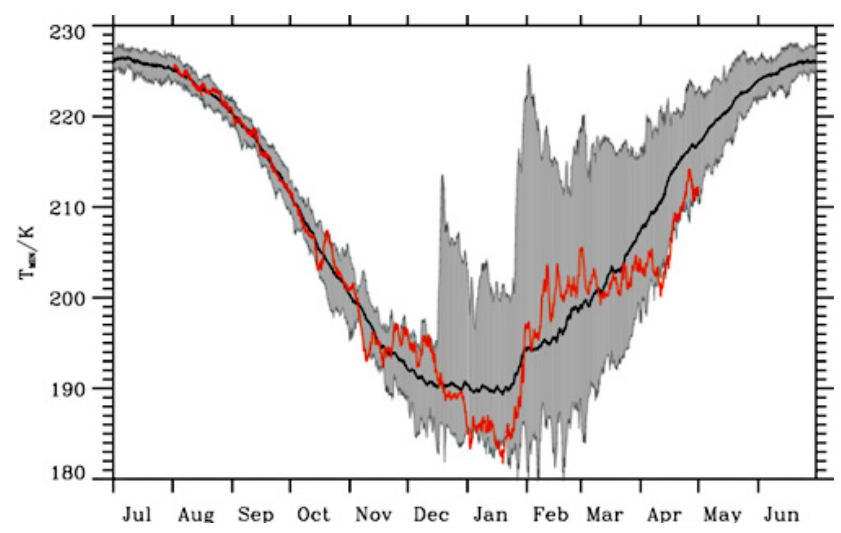

Fig. 4. Minimum temperatures $T_{\mathrm{MIN}}(\mathrm{K})$ between $65^{\circ} \mathrm{N}$ to $90^{\circ} \mathrm{N}$ at the $30 \mathrm{hPa}$ pressure surface. Black line: mean value from 1989 2009; red line the $T_{\text {MIN }}$ evolution from August 2009 through April 2010; shaded area encompasses the minimum/maximum $T_{\text {MIN }}$ between 1989 and 2009. Source: ECMWF reanalyses interim (ERA interim) data provided at 6 hourly temporal resolutions, see: http://www.ecmwf.int.

minimum temperature $\left(T_{\mathrm{MIN}}\right)$ at the $30 \mathrm{hPa}$ pressure level between $65^{\circ} \mathrm{N}-90^{\circ} \mathrm{N}$ had dropped to about $192 \mathrm{~K}$ (Fig. 4). However, the polar vortex split into two unequally strong lobes during the first ten days of December (Fig. 5, upper row) and the associated Canadian warming prevented a further decline of the minimum temperatures, resulting in $T_{\mathrm{MIN}}$ values above the climatological mean. The stronger and colder vortex lobe located over the Canadian sector of the Arctic survived this early warming event, recovered and cooled gradually through mid-January 2010 . There was a significant drop in $T_{\mathrm{MIN}}$ during this period, to values as much as $7 \mathrm{~K}$ below the climatological mean (Fig. 4). Typical flow and temperature fields from this exceptionally cold period are shown in Fig. 5 (bottom row) depicting a coherent polar vortex centered near the North Pole. Another interesting feature during this period was the frequent occurrence of wave-like structures, discernable in the stratospheric temperature and geopotential height fields (Fig. 5, bottom row). These undulations resulted from orographic gravity waves excited by the 

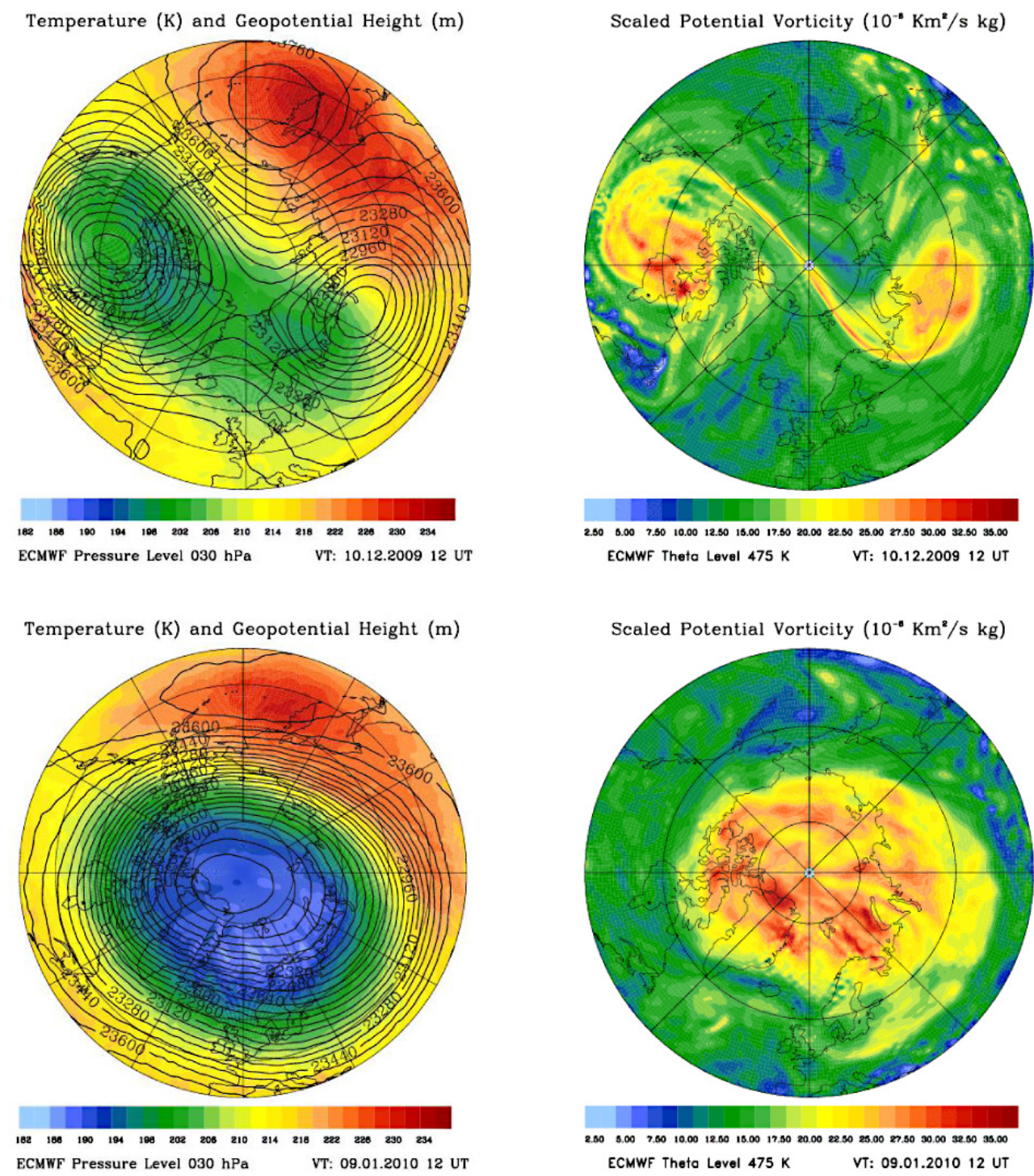

Fig. 5. Left: Absolute Temperature (K, colour shaded) and geopotential height ( $\mathrm{m}$; black contour lines) at the $30 \mathrm{hPa}$ pressure surface. Right: Scaled or modified potential vorticity PV. $(\Theta / 420 \mathrm{~K})^{-9 / 2}$ (PVU; colour shaded) at $\Theta=475 \mathrm{~K}$. Operational ECMWF T1279/L91 analyses interpolated at a regular $0.5^{\circ} \times 0.5^{\circ}$ latitude/longitude grid.

flow across Greenland. Due to the adiabatic expansion of the air flowing through these mountain waves, the actual stratospheric temperatures could have been below the $T_{\mathrm{MIN}}$ values seen in the ECMWF analyses.

During the second half of January 2010, a planetary wavenumber-one event displaced the polar vortex towards the European sector of the Arctic (see Fig. 6, upper row). This major warming event marked the start of the gradual breakup of the polar vortex. Although the vortex rapidly lost its symmetry and the cold region progressively shifted away from the vortex center (resulting in an increasing baroclinicity and susceptibility for instabilities), $T_{\mathrm{MIN}}$ inside the vortex remained below the climatological mean until the end of January 2010 at $30 \mathrm{hPa}$ (Fig. 4) and even longer at $50 \mathrm{hPa}$ (not shown). However, the intense and long-lasting disturbance of the polar vortex through the planetary wave activity resulted in a continuous warming in February 2010. Figure 6 (lower row) depicts the stratospheric flow and temperature fields in early February 2010, several days before the final vortex break-up.

It is also informative to rank the severity of the 2009-2010 Arctic winter in terms of PSC existence potential (e.g., Pawson and Naujokat, 1999; Pawson et al., 1995) relative to past Arctic winters. To do so, we utilized the temperature data record for the fifty-two year period 1958-2009 from the NCEP/NCAR Reanalysis 1 project (Kalnay et al., 1996) and estimated the relative PSC existence potential on the $30 \mathrm{hPa}$ pressure surface as the daily area of temperatures below $T_{\mathrm{NAT}}$ 

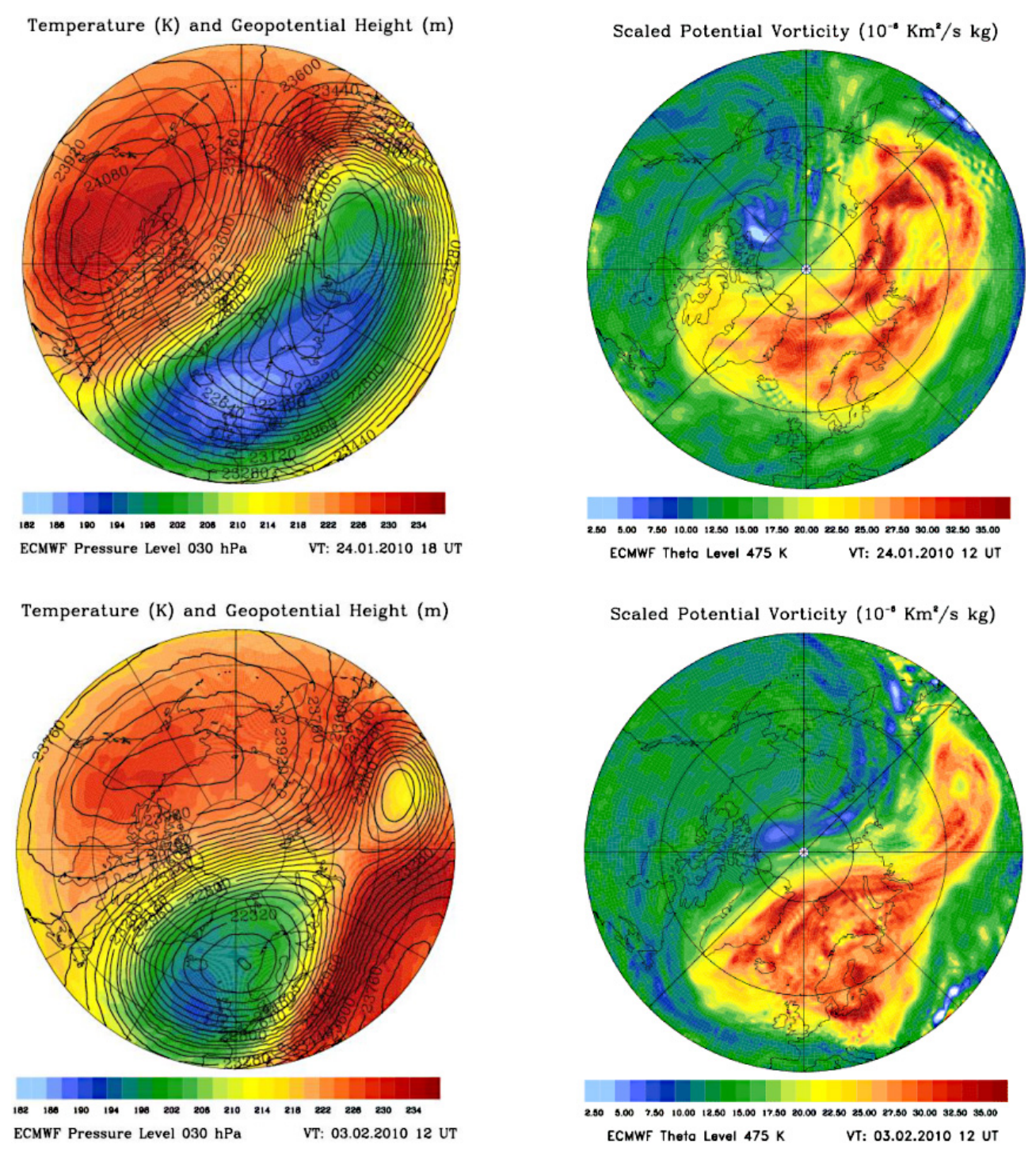

Fig. 6. left: absolute Temperature (K, colour shaded) and geopotential height (m; black contour lines) at the $30 \mathrm{hPa}$ pressure surface. Right: Scaled or modified potential vorticity PV $(\Theta / 420 \mathrm{~K})^{-9 / 2}$ (PVU; colour shaded) at $\Theta=475 \mathrm{~K}$. Operational ECMWF T1279/L91 analyses interpolated at a regular $0.5^{\circ} \times 0.5^{\circ}$ latitude/longitude grid.

and $T_{\text {ice, }}$, the equilibrium existence temperatures for NAT (Hansen and Mauersberger, 1988) and ice (List, 1984), denoted $A_{\mathrm{T}_{\mathrm{NAT}}}$ and $A_{\mathrm{T}_{\mathrm{ice}}}$, respectively. We assumed fixed values of $T_{\mathrm{NAT}}(194 \mathrm{~K})$ and $T_{\text {ice }}(185 \mathrm{~K})$ corresponding to the average Aura Microwave Limb Sounder (MLS) $\mathrm{HNO}_{3}$ and $\mathrm{H}_{2} \mathrm{O}$ mixing ratios at $30 \mathrm{hPa}$ from $\mathrm{PSC}$-free periods of early December 2006-2009. Although $A_{\mathrm{T}_{\mathrm{NAT}}}$ likely overestimates the true areal coverage of PSCs (Pitts et al., 2007), it is a good gauge of the extent of cold air in the stratosphere on any day and a relative measure of potential PSC existence. $A_{\mathrm{T}_{\text {ice }}}$ provides insight to both the overall "depth" of the coldness and the potential existence of synoptic-scale regions of ice clouds. However, $A_{\mathrm{T}_{\mathrm{ice}}}$ is not a reliable indicator of mountain wave ice cloud existence since mesoscale temperature pertur- bations below $T_{\text {ice }}$ such as those induced by mountain waves are not resolved in the $2.5^{\circ} \times 2.5^{\circ}$ gridded NCEP/NCAR Reanalysis dataset. Figure 7 depicts the $A_{\mathrm{T}_{\mathrm{NAT}}}$ (top panel) and $A_{\mathrm{T}_{\text {ice }}}$ (bottom panel) statistics at $30 \mathrm{hPa}$ for the NovemberMarch period. In each figure, the fifty-two year daily average area is depicted by the black dotted curves, the daily 95th percentile value is represented by the upper limit of the gray-shaded region, and the daily values for the 2009-2010 winter are denoted by the red curves. Consistent with the period of unusually low $T_{\mathrm{MIN}}$ seen in Fig. 4 , there was an extended period of large $A_{\mathrm{T}_{\mathrm{NAT}}}$ in 2009-2010. Daily values of $A_{\mathrm{T}_{\mathrm{NAT}}}$ exceed the fifty-two year average from mid-December through late January and were above the 95 th percentile (i.e., in the top three years) during much of January. The depth 

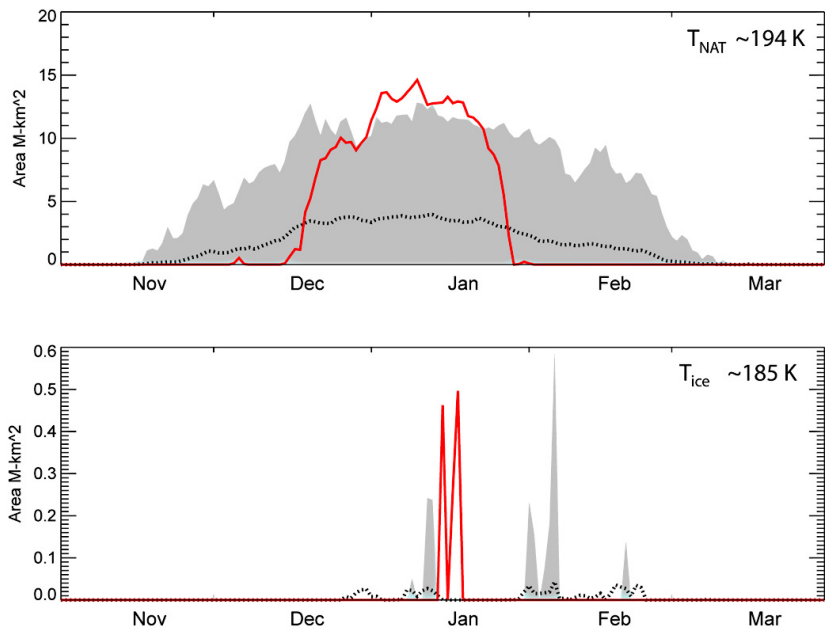

Fig. 7. $A_{\mathrm{T}_{\mathrm{NAT}}}$ (top panel) and $A_{\mathrm{T}_{\text {ice }}}$ (bottom panel) statistics at $30 \mathrm{hPa}$ for the November-March period based on the temperature record for the 52-yr period 1958-2009 from the NCEP/NCAR Reanalyses 1 project. In each figure, the 52-yr daily average area is depicted by the black dotted curves, the daily 95 th percentile value is represented by the upper limit of the gray-shaded region, and the daily values for the 2009-2010 winter are denoted by the red curves.

of the cold air reached a peak during 15-21 January 2010 when synoptic-scale areas of $A_{\mathrm{T}_{\text {ice }}}$ were observed on a series of days. The $A_{\mathrm{T}_{\text {ice }}}$ values during this week were larger than the values for all but a few days over the past fifty-two year, underscoring how unique the 2009-2010 winter was in this regard. Although the 2009-2010 PSC season was relatively short due to the early major warming, the extent and depth of the cold air during the RECONCILE field campaign in January 2010 has rarely been seen over the past half-century.

The strong coupling between the evolution of the vortex and its associated cold pool and the actual occurrence of PSCs is clearly illustrated in Fig. 8 which shows a series of five-day composite maps of CALIPSO PSC frequency (fraction of observations identified as PSCs) at an altitude of $22 \mathrm{~km}$ (approximately $30 \mathrm{hPa}$ ) for the 2009-2010 winter. Overlaid on the figures are contours of $T_{\mathrm{NAT}}$ and $T_{\text {ice }}$ based on Goddard Earth Observing System (GEOS-5) gridded temperature data used in the CALIPSO Level 1 data processing. Values of $T_{\mathrm{NAT}}$ and $T_{\text {ice }}$ were calculated using estimates of the total abundances of $\mathrm{HNO}_{3}$ and $\mathrm{H}_{2} \mathrm{O}$ derived from daily averages of Aura MLS observations from cloud-free regions of the vortex. During the season, the spatial extent of the CALIPSO PSC observations corresponds well with the region of temperatures below $T_{\mathrm{NAT}}$. Scattered patches of clouds were first observed in mid-December over Greenland as the vortex initially cooled below $T_{\mathrm{NAT}}$. As the vortex continued to strengthen and cool, PSCs became widespread by early January and then persisted until late January when the major stratospheric warming occurred and ended the PSC season. Of particular note is the five-day
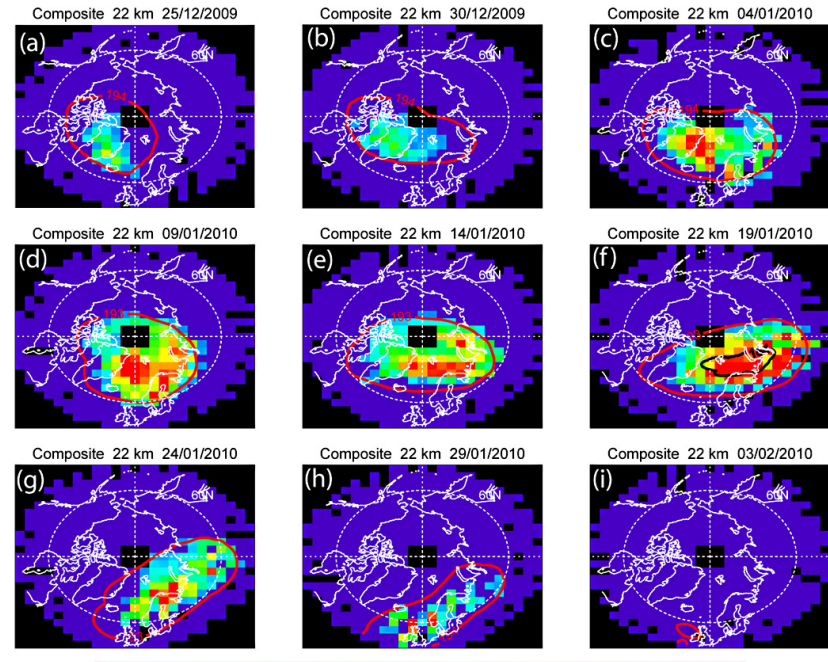

0.0

0.20

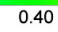

PSC Frequency
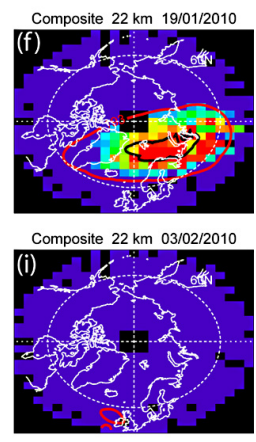

Fig. 8. Five-day composites of CALIPSO PSC frequency (number of PSC observations/total number of observations) at an altitude of $22 \mathrm{~km}$ (approximately $30 \mathrm{hPa}$ ) during the 2009-2010 Arctic winter. Contours of $T_{\mathrm{NAT}}$ (red) and $T_{\text {ice }}$ (black) are indicated on the figures.

period ending 19 January (Fig. 8f) when the vortex cooled below $T_{\text {ice }}$ at $22 \mathrm{~km}$ over a large region between roughly $70^{\circ}-80^{\circ} \mathrm{N}$ latitude and $10^{\circ} \mathrm{W}-80^{\circ} \mathrm{E}$ longitude. Although mesoscale cooling events associated with mountain waves commonly produce localized temperature excursions below $T_{\text {ice }}$ (e.g., Dörnbrack and Leutbecher, 2001), synoptic-scale regions below $T_{\text {ice }}$ such as observed in mid-January 2010 are unusual in the Arctic (Pawson et al., 1995). As we discuss later, this particular event led to a rare outbreak of synopticscale ice PSCs.

\section{Comparison of 2009-2010 CALIPSO PSC data with prior years}

The 2009-2010 PSC season was the most intense of the fouryear CALIPSO PSC data record. Figure 9 shows the areal coverage of PSCs observed by CALIPSO in the Arctic for each of the past four winters as a function of altitude and time. The significant year-to-year differences in the observed PSC areal coverage illustrate the large interannual variability associated with Arctic PSC activity where the seasonal evolution of the vortex each winter is quite different with no real "typical" year. Although the PSC season was longer in some earlier years (e.g., 2006-2007 and 2007-2008), the areal extent of PSCs during the 2009-2010 winter was significantly larger than observed in any of the previous three winters, which is consistent with the abnormally cold temperatures observed during this winter (Figs. 4 and 7). In fact, the season total volume of PSCs (areal extent integrated over time and altitude) observed during the 2009-2010 winter was 

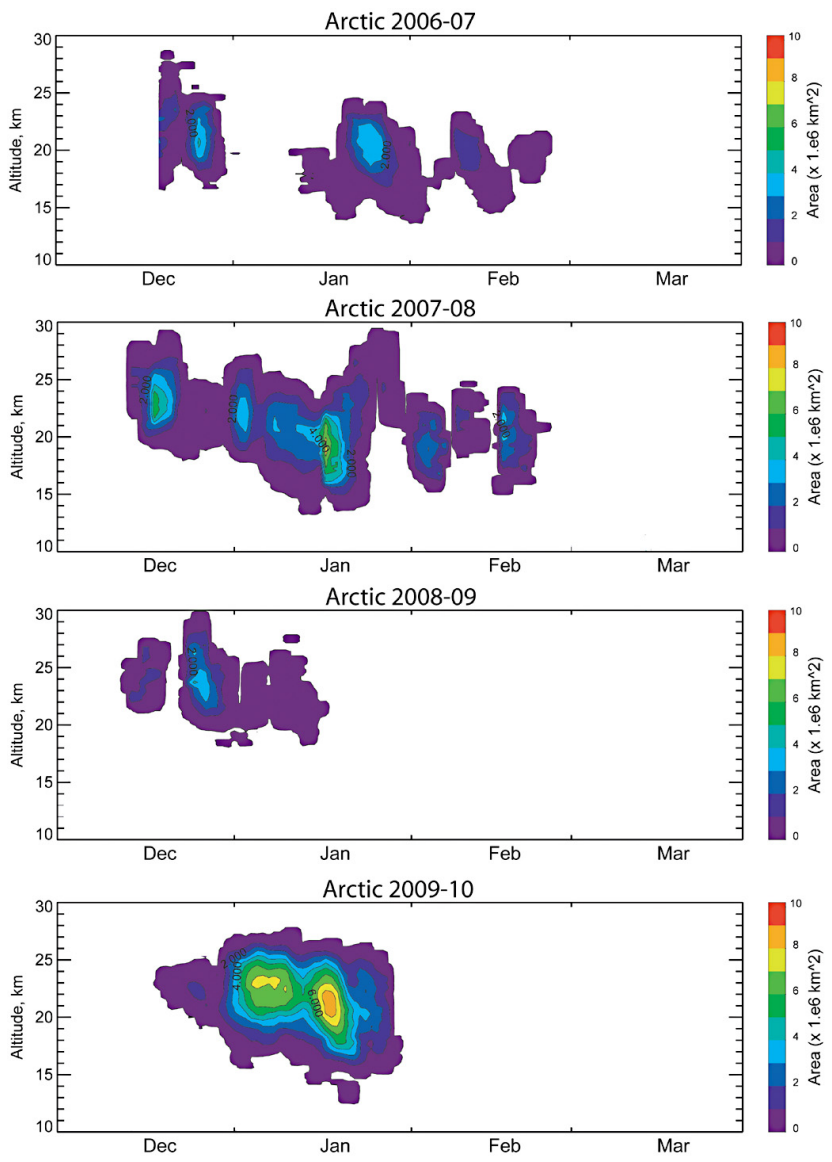

Fig. 9. Daily areal coverage of PSCs as a function of altitude for the four Arctic winters in the CALIPSO data record to date.

nearly as large as the total from the three previous seasons combined.

The CALIPSO dataset also provides the unique opportunity to examine how the Arctic PSC composition characteristics in 2009-2010 compare with previous years. Figure 10 shows composite 2-D histograms of CALIPSO PSC observations from each of the past four Arctic seasons in the $\delta_{\text {aerosol }}$ vs. $1 / R_{532}$ coordinate system, with the domains of the CALIPSO PSC composition classes overlaid. The total number of CALIPSO PSC observations in each year is indicated above the color bar in each panel. In addition to there being many more PSC observations during the 2009-2010 season, there are also unique composition differences relative to previous years. A particularly striking feature of the 2009-2010 winter is the abundance of ice clouds, with large numbers of observations spread throughout the ice cloud optical domain (Fig. 10d). These widespread ice cloud observations occurred primarily during the week of 15-21 January when the vortex cooled below $T_{\text {ice }}$ over synoptic scales as noted in the previous section. In most previous winters (i.e., 20072008 and 2008-2009), CALIPSO ice cloud observations are limited to a small number of mountain wave induced events.
Another notable feature of the 2009-2010 winter is the large number of Mix 2 and Mix 2-enh PSC observations. In the following section, we will explore these unique aspects of the 2009-2010 season in more detail in attempt to understand the underlying physical mechanisms.

\section{2009-2010 PSC season in detail}

Through our examination of the 2009-2010 season, we found that it can roughly be divided into four time periods with distinctly different PSC optical characteristics. Figure 11 shows composite 2-D normalized histograms of CALIPSO PSC observations from each of these four periods over the altitude range from $15-30 \mathrm{~km}$ in the $\delta_{\text {aerosol }}$ vs. $1 / R_{532}$ coordinate system. The early season (15-30 December 2009), shown in Fig. 11a, was dominated by patchy, tenuous clouds that can be characterized as liquid/NAT mixtures with NAT particles occurring in low numbers/volumes, falling predominantly into the Mix 1 domain. These tenuous PSCs were first detected by CALIPSO on 15 December and at least a few patches of clouds were observed on each day of this period. No mountain wave ice PSCs were observed by CALIPSO during this initial period. Since CALIPSO does not sample the entire stratospheric volume, we can not preclude the possibility that isolated, small-scale wave clouds occurred, but it is quite unlikely since meteorological conditions during this period were not conducive to mountain wave ice cloud formation. The detection of NAT particles in December, prior to any observed mountain wave ice PSCs, corroborates the conclusions of Voigt et al. (2005) and Pagan et al. (2004) that ice nuclei are not a prerequisite for NAT formation. A non-ice NAT nucleation mechanism operating on vortex-wide scales would have important implications for denitrification and potential enhancement of ozone depletion. Further investigation is warranted to understand the details of this nucleation mechanism, determine the source of the nuclei, and to see if there is evidence in the CALIPSO data for this mechanism in other seasons in the Arctic and also in the Antarctic. Particle measurements from the Geophysica flights during RECONCILE may provide insight to potential sources of NAT nuclei. Examples of CALIPSO PSC observations from this period are shown in Fig. 12. The figure shows images of CALIPSO PSC observations, color-coded by composition class, from a sequence of four orbits sweeping across the vortex on 24 December 2009. On the right of each composition image is a map of GEOS-5 temperature and geopotential height fields at $30 \mathrm{hPa}$, with the corresponding CALIPSO orbit track overlaid as the solid white line. The composition images shown in Fig. 12 illustrate the patchy nature of the clouds observed by CALIPSO during December when it was only marginally cold enough to support PSC formation. A complete set of CALIPSO composition images from the entire 2009-2010 winter is provided as supplemental material. 

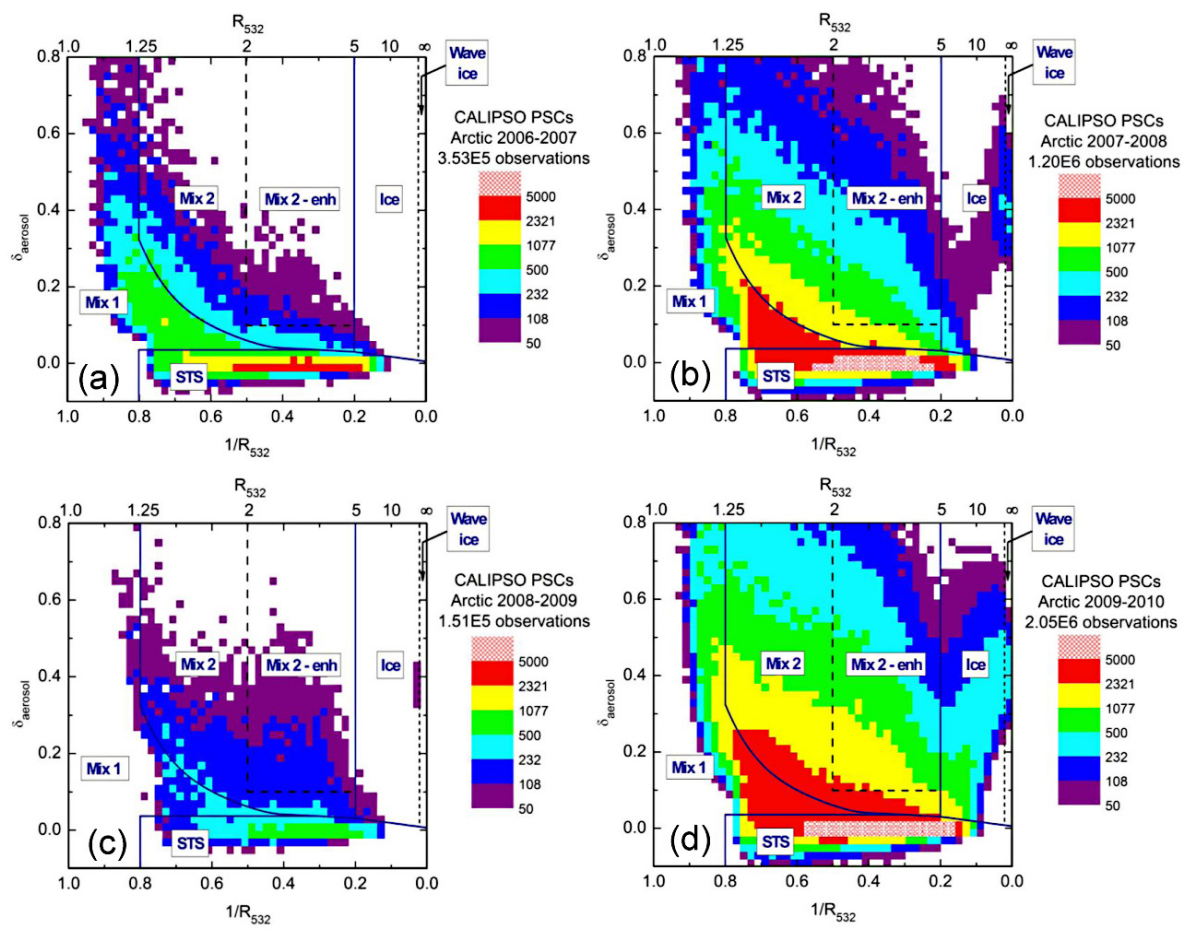

Fig. 10. Composite 2-D histograms of CALIPSO PSC observations from each of the last four Arctic seasons in the $\delta_{\text {aerosol }}$ vs. $1 / R_{532}$ coordinate system, with the domains of the CALIPSO PSC composition classes overlaid.
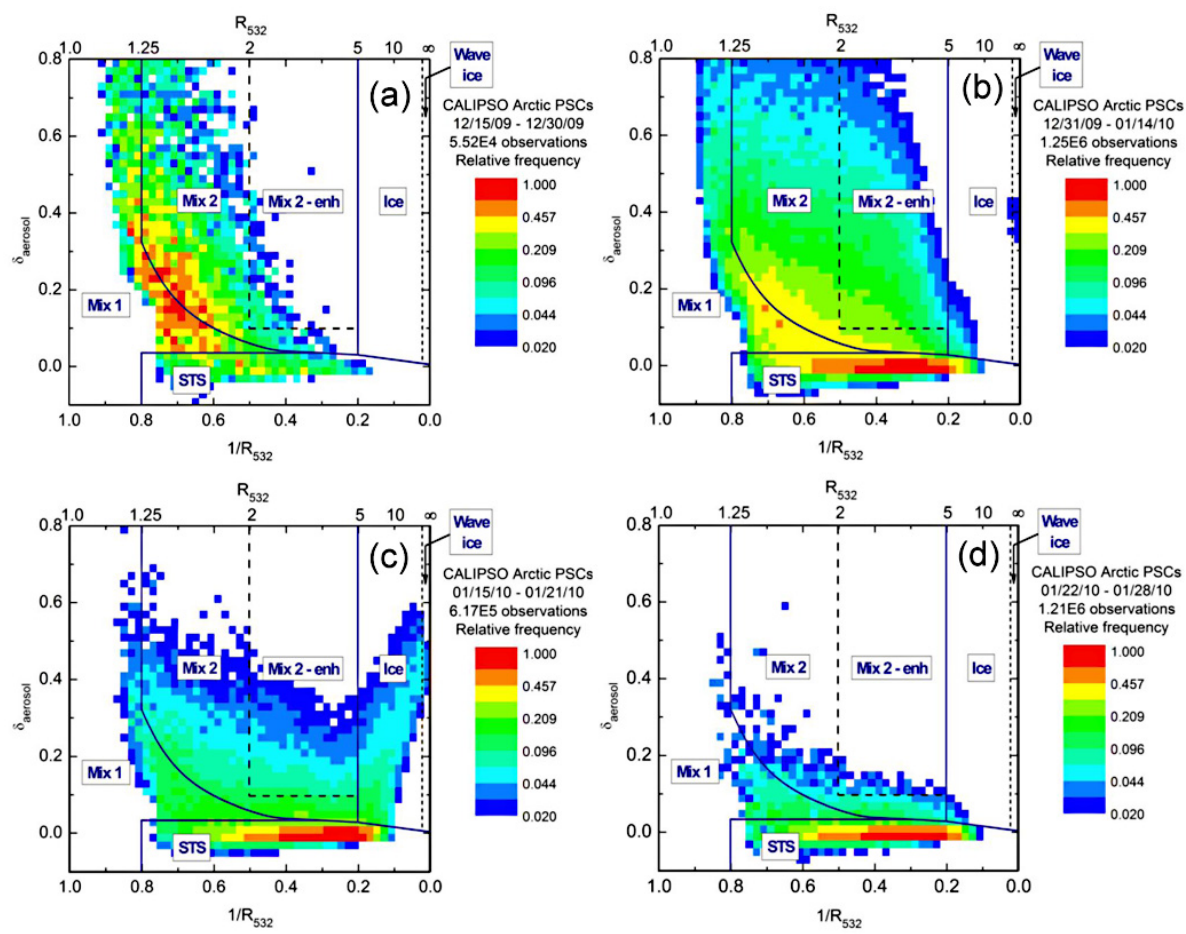

Fig. 11. Normalized composite 2-D histograms of CALIPSO PSC observations from each of four periods during the 2009-2010 Arctic winter over the altitude range from $15-30 \mathrm{~km}$ in the $\delta_{\text {aerosol }} \mathrm{vs.} 1 / R_{532}$ coordinate system. 

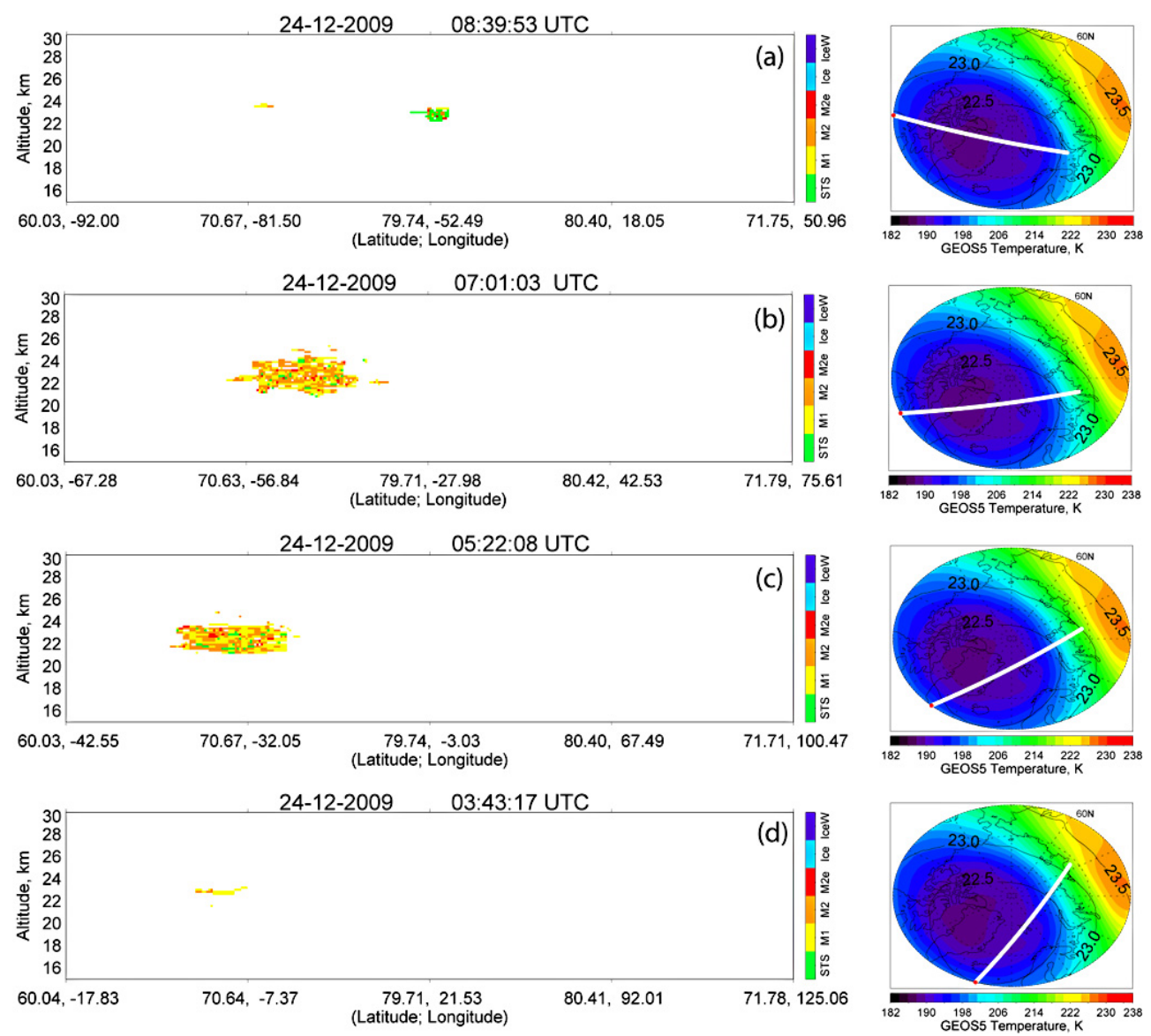

Fig. 12. Examples of CALIPSO PSC composition observations from four consecutive orbits during 24 December 2009. GEOS5 temperature and geopotential height fields at $30 \mathrm{hPa}$ for 12:00 UTC are shown on the right with the location of the corresponding CALIPSO orbit tracks indicated by the white lines.

The nature of the season changed abruptly on 31 December with the first observations of mountain wave ice clouds. This initiates the second phase of the PSC season (31 December-14 January) that was characterized by numerous mountain wave ice cloud events along the east coast of Greenland. The 2-D histogram from this period is shown in Fig. 11b. The cluster of observations with very large scattering ratio values at the right edge of the ice domain corresponds to the mountain wave ice PSC observations. This second phase was also marked by a dramatic increase in observations of Mix 2 and Mix 2-enh clouds, as well as fully developed liquid STS clouds. Figure 13 shows examples of CALIPSO composition images from this period (4 January). A distinct mountain wave ice cloud event $(R>50$ denoted by dark blue pixels) is visible in Fig. $13 \mathrm{~b}$ at an altitude of $25 \mathrm{~km}$ near $70^{\circ} \mathrm{N}, 28^{\circ} \mathrm{W}$ along the east coast of Greenland. Along the orbit track west of the mountain wave cloud (Fig. 13a), PSC composition is predominately liquid STS. Along orbits east of the wave cloud (Fig. 13c-e), the PSCs consist mostly of liquid/NAT mixtures, including distinct regions of Mix 2-enh clouds. This pattern of predominantly liquid STS clouds occurring west (generally upstream) and liquid/NAT mixtures occurring east (generally downstream) of wave ice clouds was frequently observed during this period, suggesting that NAT nucleation by wave ice clouds was a major source of the widespread NAT particles observed during this period. This has been observed by others on more limited scales in the Arctic (e.g., Carslaw et al., 1998; Dörnbrack et al, 2002; Fueglistaler et al., 2002; Voigt et al., 2003).

Figure 14a shows the locations of all CALIPSO observations identified as mountain wave ice clouds $\left(R_{532}>50\right)$ during the 31 December-14 January period. Figure 14b shows analyzed locations for stratospheric mountain wave activity for the same period based on the ECMWF horizontal divergence (DIV) at $30 \mathrm{hPa}$ (see Plougonven et al., 2003 for the use of DIV as an indicator of mountain wave activity). CALIPSO observed numerous mountain wave ice clouds along Greenland's east coast, in agreement with the maximum in mountain wave activity indicated in the ECMWF analyses. CALIPSO also observed a few wave ice clouds over northern Scandinavia on 10 January, which corresponds well with the short-lived $(<24 \mathrm{~h})$ mountain wave 

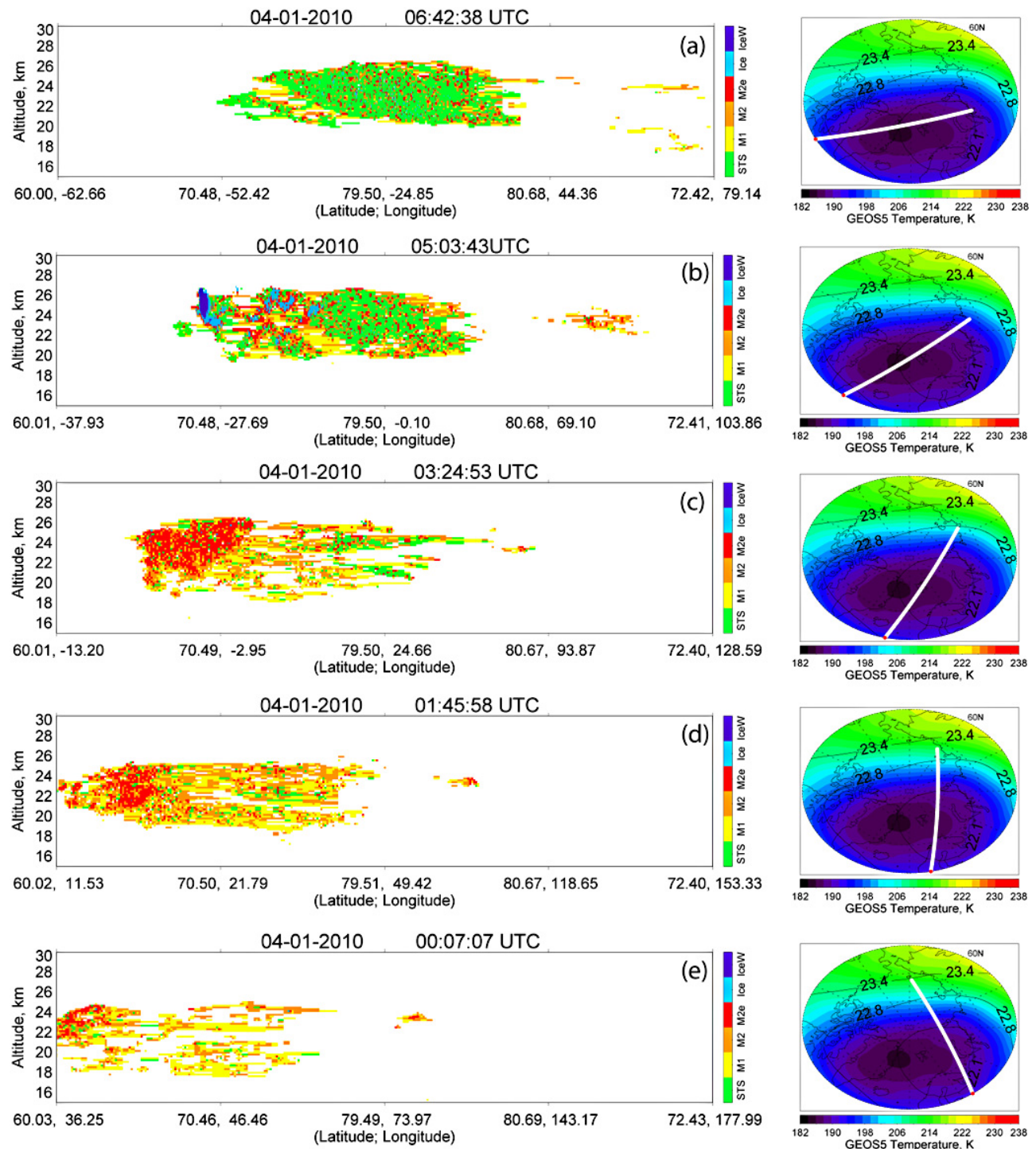

Fig. 13. Examples of CALIPSO PSC composition observations from five consecutive orbits during 4 January 2010. GEOS5 temperature and geopotential height fields at $30 \mathrm{hPa}$ for 12:00 UTC are shown on the right with the location of the corresponding CALIPSO orbit tracks indicated by the white lines.

event on 10-11 January depicted in the ECMWF analyses over northern Scandinavia. The overall agreement between the locations of CALIPSO wave ice clouds and the ECMWF analyzed mountain waves provides confidence that the CALIPSO wave cloud discrimination approach is robust.

The third distinct phase in the PSC season occurred the week of 15-21 January when a region of the vortex cooled below the frost point (see Figs. 7 and 8f), resulting in an extensive region of synoptic-scale ice PSCs. The 2-D histogram of CALIPSO PSC observations from this phase is shown in Fig. 11c. The relative maximum in the frequency of PSC observations extending upward to the right in the ice domain is the distinctive signature of synoptic-scale ice clouds as commonly seen during the Antarctic winter (e.g. P09).
Also note that the relative number of observations in the Mix 1, Mix 2, and especially Mix 2-enh domains decreased significantly during this phase compared with the previous phase (Fig. 11b). The increase in ice PSC observations and concomitant decrease in NAT mixture observations may be an indicator that heterogeneous nucleation on pre-existing NAT particles is an important mechanism for formation of synoptic-scale ice PSCs. Examples of CALIPSO composition images from this period (18-19 January) are shown in Fig. 15. As was common during this week, large regions of ice clouds were observed by CALIPSO near the center of the cold pool (roughly north of Scandinavia, east of Spitsbergen, and west of Novaya Zemlya) at altitudes between 20-25 km (Fig. 15c-d). To the west of this ice region, STS 


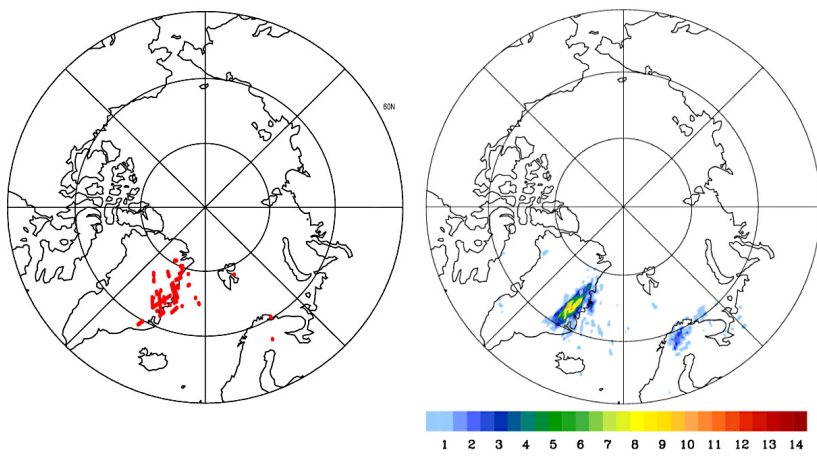

Fig. 14. Locations of wave ice PSCs as observed by CALIPSO ( $R>50)$ during 31 December 2009-14 January 2010 (left panel) and mountain wave occurrence (number of six-hourly events) as derived from the ECMWF horizontal divergence conditions DIV $>2 \times 10^{-4} \mathrm{~s}^{-1}$ (right panel) at $30 \mathrm{hPa}$ for the same period. Operational ECMWF T799 analyses interpolated at a regular $0.5^{\circ} \times 0.5^{\circ}$ latitude/longitude grid.

was widespread (Fig. 15a-b), while liquid/NAT mixtures, including Mix 2-enh, were predominant along the eastern end of the cold pool (Fig. 15e). Also note that wave ice clouds ( $R>50$, denoted by dark blue pixels) were occasionally embedded in the large-scale regions of ice, such as seen near Novaya Zemlya (Fig. 15d). This is consistent with ECMWF analyzed mountain wave occurrence during this period (not shown).

Widespread ice PSC observations disappeared abruptly after 21 January as the vortex warmed above the frost point, signalling the transition to the last phase of the PSC season that lasted from 22-28 January. With the exception of a few wave ice PSCs, no ice clouds were observed during this period. The 2-D histogram of PSC observations from this last period, shown in Fig. 11d, is strikingly different than those of any of the previous periods. STS observations dominate this final phase with essentially no ice PSCs and many fewer liquid/NAT mixtures than in the previous two periods. Examples of CALIPSO composition images from this period (2223 January) are shown in Fig. 16. Extensive areas of STS clouds (Fig. 16a-c) were observed by CALIPSO in the cold pool, which was displaced well south and west of the vortex center. Only patchy regions of NAT mixtures were observed, primarily on the eastern side of the cold pool. There are several possible explanations for the dramatic reduction in NAT mixture observations. Wave ice PSCs, a primary source of NAT nuclei, were limited during this period and occurred on the eastern side of the cold pool. Secondly, the displacement of the cold pool from the vortex center limits NAT particle growth, which increases the likelihood that any NAT particles present were masked by STS at colder temperatures. After 28 January, the vortex broke down and no more PSCs were observed by CALIPSO.

P09 showed that there were distinct variations in PSC composition with altitude over the course of the season in the
Antarctic. Following a similar approach, Fig. 17 shows the relative proportion of PSCs observed in the different composition classes as a function of altitude and time during the 2009-2010 Arctic season. For reference, maximum temperature departures from $T_{\mathrm{NAT}}$, based on Aura MLS $\mathrm{HNO}_{3}$ and $\mathrm{H}_{2} \mathrm{O}$ mixing ratio observations and GEOS-5 temperature analyses, are shown in Fig. 17a. Low number density liquid/NAT mixtures (Fig. 17b) were the most frequently observed composition class early in the season and in the lower altitude regions of the clouds (below $\sim 18-20 \mathrm{~km}$ ) throughout the season. The predominance of Mix 1 in the lower regions of the clouds is consistent with CALIPSO observations in the Antarctic and corresponds well with the altitude region where the temperature departures below $T_{\mathrm{NAT}}$ are smallest $\left(T-T_{\mathrm{NAT}}<-4 \mathrm{~K}\right)$ (see Fig. 17a). Temperatures in this regime are above the threshold where STS particles begin to grow substantially and, hence, there is a better likelihood of CALIPSO detecting the presence of low numbers of relative large NAT particles characterized by the Mix 1 class. Higher number density liquid/NAT mixtures (Mix 2 and Mix 2-enh) become the majority composition observed above $20 \mathrm{~km}$ during roughly the first half of January (Fig. 17c, d) which corresponds well with the period of wave ice cloud activity from 31 December-14 January. The widespread synoptic-scale ice episode is depicted by the relative maximum in ice PSC observations during the third week of January in Fig. 17e. Immediately following this period of widespread ice PSCs, STS becomes the most frequent composition observed above about $18 \mathrm{~km}$ (Fig. 17f). The transition of the dominant composition class above $18 \mathrm{~km}$ from Mix 2 and Mix 2-enh before the widespread ice event to STS after the ice event is consistent with the change in the dynamical flow regime that occurred in mid-January, as discussed earlier.

The spatial patterns of PSC composition observed by CALIPSO during the active mountain wave period (31 December-14 January) are consistent with the NAT "mother cloud" conceptual model (e.g., Fueglistaler et al., 2002; Dhaniyala et al., 2002; Mann et al., 2005) whereby mountain wave ice clouds nucleate high number density NAT clouds ("mother clouds") with widespread regions of lower number density NAT mixtures (Mix 1) below these clouds.

\section{Summary and conclusions}

An intensive field campaign focused on measurements related to PSCs and ozone chemistry was conducted in the Arctic during January-March 2010 as part of the European Union RECONCILE project. To complement the more focused measurements from the RECONCILE field campaign, we have used spaceborne lidar measurements from CALIPSO to characterize PSC occurrence and composition during the 2009-2010 season on vortex-wide scales. We have expanded the CALIPSO PSC composition definitions from P09 to include two new sub-classes: Mix 2-enh, which 

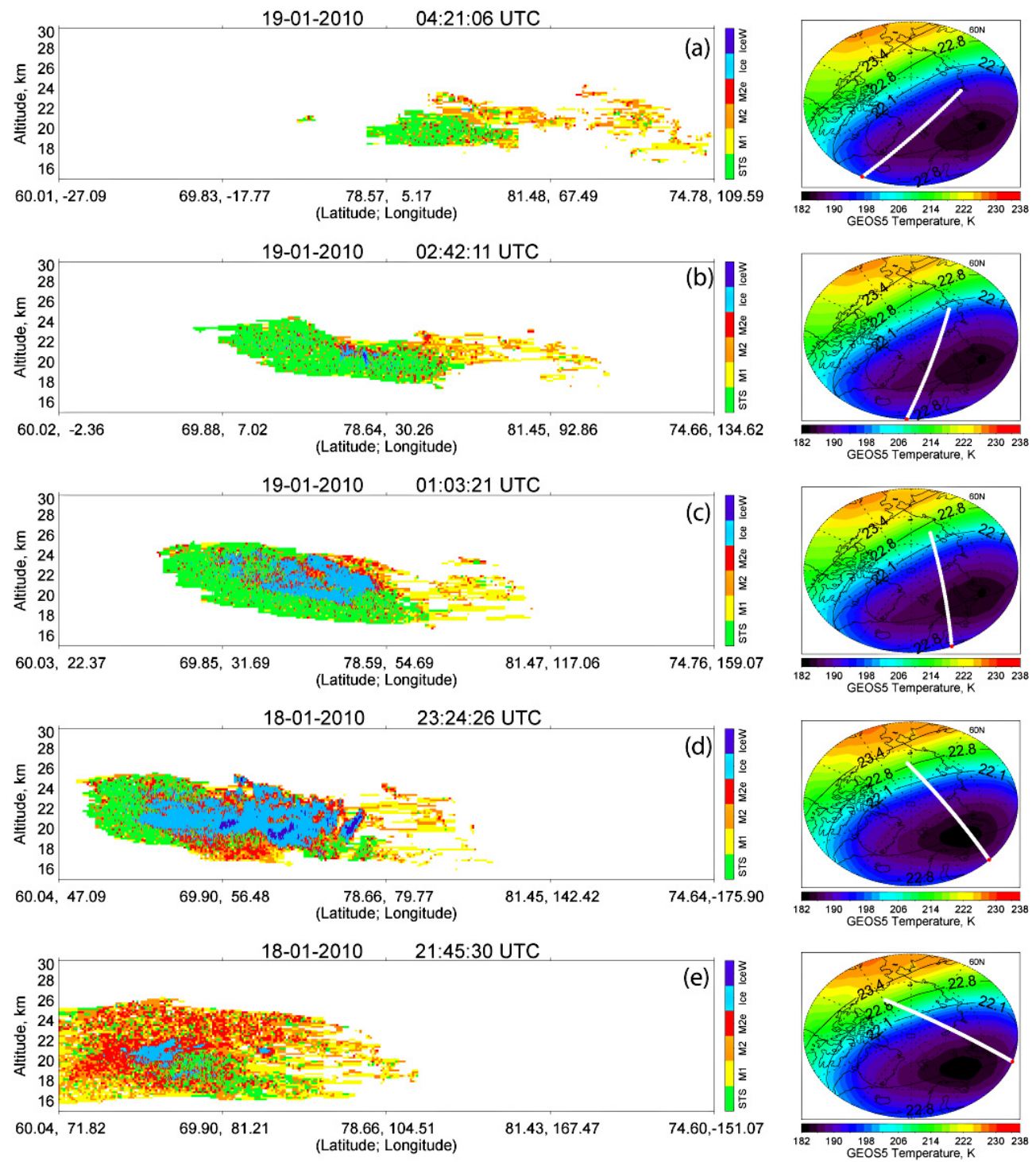

Fig. 15. Examples of CALIPSO PSC observations from five consecutive orbits during 18-19 January 2010. GEOS5 temperature and geopotential height fields at $30 \mathrm{hPa}$ for 12:00 UTC 18 January are shown on the right with the location of the corresponding CALIPSO orbit tracks indicated by the white lines.

have the characteristics of higher number density NAT mixtures similar to Type 1a-enhanced identified in earlier Arctic studies, and mountain wave ice clouds characterized by high particle number densities but relatively small particles.

Compared to winters over the past half-century, the 20092010 winter was unusually cold from mid-December through January and one of only a few winters with synoptic-scale temperatures below $T_{\text {ice }}$. The 2009-2010 winter was also exceptional from the CALIPSO perspective with more PSCs observed than in the three previous Arctic seasons combined. The distribution of PSCs among the various composition classes was also different during the 2009-2010 winter with significantly more observations of ice clouds and higher number density NAT mixtures (Mix 2 and Mix 2-enh).
We found that the 2009-2010 season can roughly be divided into four time periods displaying different PSC optical characteristics. The first period (15-30 December) was marked by patchy, tenuous PSCs that were primarily liquid/NAT mixtures with low NAT number densities. The observation of widespread NAT mixtures prior to any observations of ice clouds suggests that a non-ice related NAT nucleation process operates on vortex wide scales. This could have significant implications in terms of denitrification and potentially enhanced ozone loss. The second period (31 December-14 January) was characterized by numerous wave ice clouds and a dramatic increase in liquid/NAT mixtures with higher NAT number densities (especially Mix 2-enh) and fully-developed STS. From an overall 

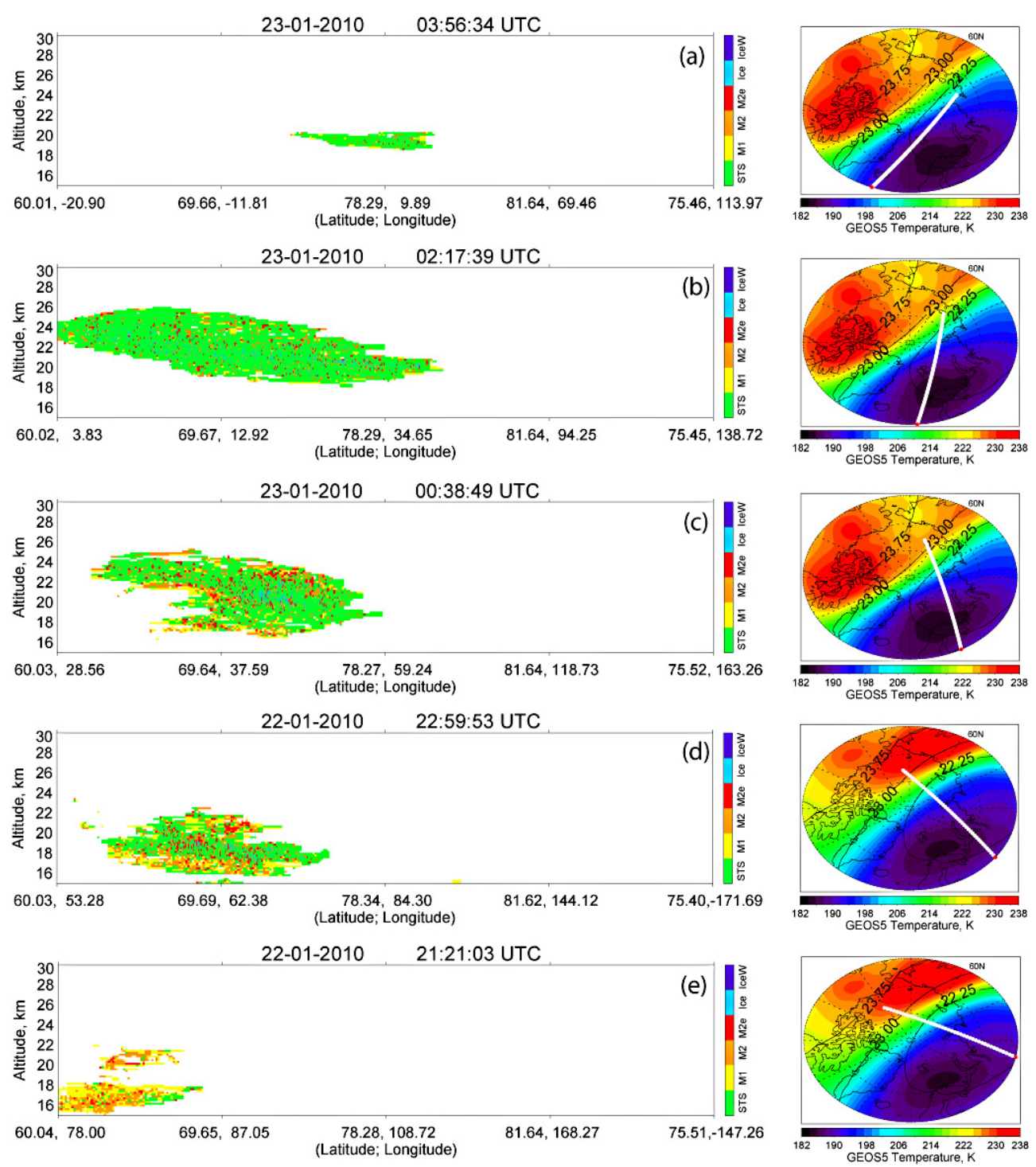

Fig. 16. Examples of CALIPSO PSC observations from five consecutive orbits during 22-23 January 2010. GEOS5 temperature and geopotential height fields at $30 \mathrm{hPa}$ for 12:00 UTC 23 January are shown on the right with the location of the corresponding CALIPSO orbit tracks indicated by the white lines.

vortex perspective, the STS PSCs occurred upstream of the wave ice events, whereas liquid/NAT mixtures were observed downstream of the wave clouds, including distinct contiguous regions of Mix 2-enh PSCs. During the third phase (1521 January), synoptic-scale ice clouds were observed over regions of the vortex that had cooled below the frost point. With the appearance of synoptic-scale ice clouds there was a noticeable decrease in liquid/NAT mixtures, suggesting that heterogeneous nucleation on pre-existing NAT particles may be an important mechanism for formation of synoptic-scale ice PSCs. The fourth period (22-28 January) was dominated by STS PSCs, with essentially no ice clouds and distinctly fewer observations of liquid/NAT mixtures than in any of the three earlier periods. The apparent disappearance of liq-
uid/NAT mixtures is a result of many fewer wave ice clouds - a primary source of NAT nuclei - as well as a displacement of the cold pool away from the vortex center, which limited NAT particle growth and increased the likelihood of NAT particles being masked by STS droplets at low temperatures.

We also found interesting variations in PSC composition with altitude over the course of the 2009-2010 Arctic season. Lower number density liquid/NAT mixtures were most frequently observed in the lower altitude regions of the clouds (below $\sim 18-20 \mathrm{~km}$ ), which is consistent with CALIPSO observations in the Antarctic. Higher number density liquid/NAT mixtures, especially Mix 2-enh, were most frequently observed at altitudes above $18-20 \mathrm{~km}$, primarily 

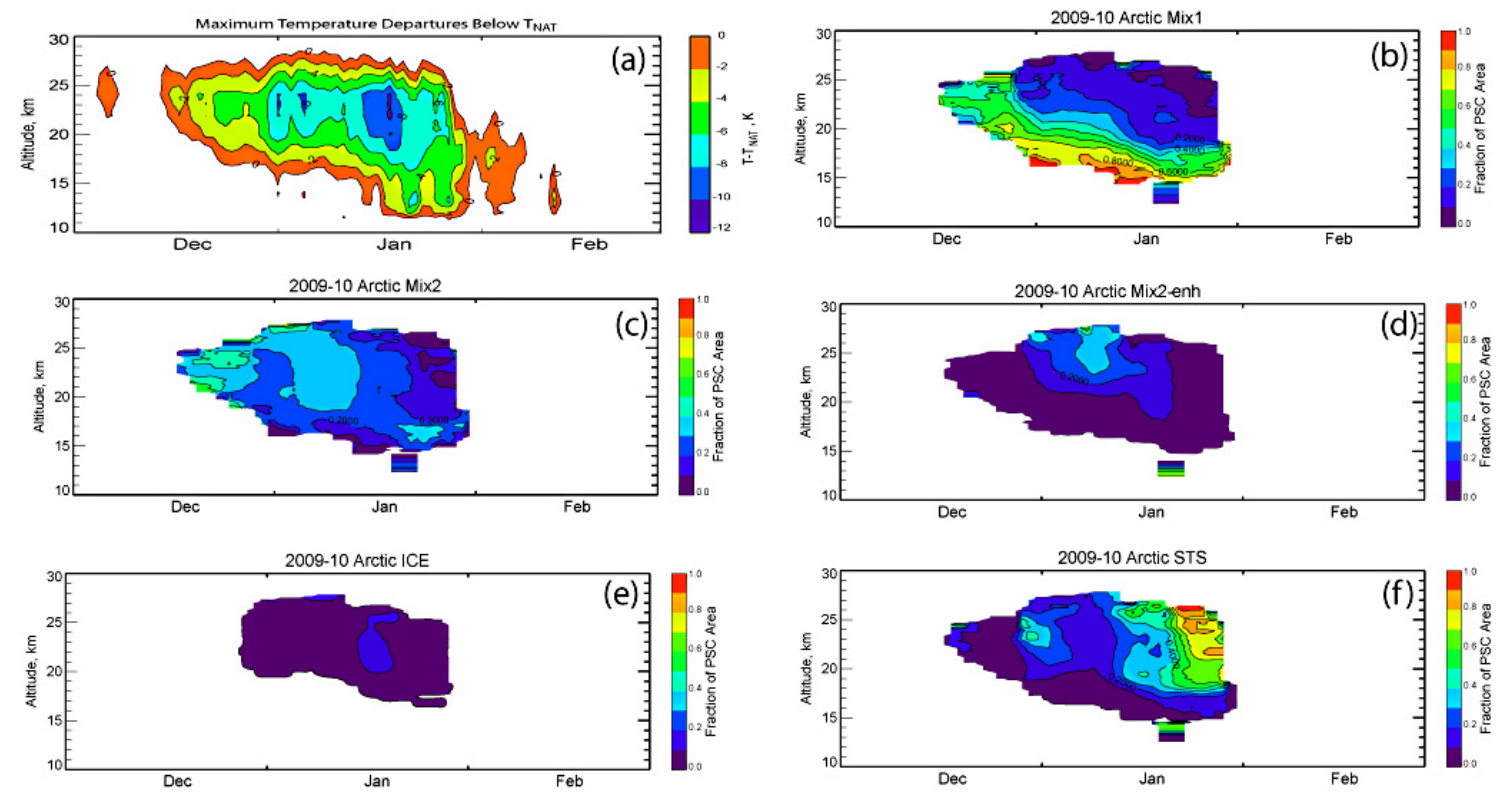

Fig. 17. Relative proportion of PSCs observed in the (b) Mix 1, (c) Mix 2, (d) Mix 2-enh, (e) ice, and (f) STS composition classes as a function of altitude and time. For reference, the maximum temperature departure from $T_{\mathrm{NAT}}$ derived from GEOS-5 analyses is shown in panel (a).

downstream of wave ice clouds. This pattern is consistent with the conceptual model whereby low number density, large NAT particles are precipitated from higher number density NAT clouds (i.e. mother clouds) that are nucleated downstream of mountain wave ice clouds.

\section{Supplementary material related to this article is available online at: http://www.atmos-chem-phys.net/11/2161/2011/ acp-11-2161-2011-supplement.zip.}

Acknowledgements. The Aura MLS gas species data were provided courtesy of the MLS team and obtained through the Aura MLS website (http://mls.jpl.nasa.gov/index-eos-mls.php). The NCEP Reanalysis data were provided by the NOAA/OAR/ESRL PSD, Boulder, Colorado, USA, and obtained from their Web site at http://www.esrl.noaa.gov/psd/. The ECMWF data were available through the special project "Effect of nonhydrostatic gravity waves on the stratosphere above Scandinavia" by one of the authors (A.D.). The field activities in Kiruna were funded by the EC as part of the FP7 project RECONCILE (Grant number: RECONCILE226365-FP7-ENV-2008-1). We would also like to thank Dr. Hal Maring, NASA Radiation Sciences Program manager, and Dr. David Considine, Program Scientist for the CALIPSO/CloudSat Missions for continued support of this research. Support for L. Poole is provided under NASA contract NNL07AA00C.

Edited by: R. MacKenzie

\section{References}

Biele, J., Tsias, A., Luo, B. P., Carslaw, K. S., Neuber, R., Beyerle, G., and Peter, T.: Nonequilibrium coexistence of solid and liquid particles in Arctic stratospheric clouds, J. Geophys. Res., 106, 22991-23007, 2001.

Blum, U., Fricke, K. H., Müller, K. P., Siebert, J., and Baumgarten, G.: Long-term lidar observations of polar stratospheric clouds at Esrange in northern Sweden, Tellus, 57B, 412-422, 2005.

Buss, S., Hertzog, A., Hostettler, C., Bui, T. B., Lüthi, D., and Wernli, H.: Analysis of a jet stream induced gravity wave associated with an observed ice cloud over Greenland, Atmos. Chem. Phys., 4, 1183-1200, doi:10.5194/acp-4-1183-2004, 2004.

Cairo, F., Di Donfrancesco, G., Adriani, A., Pulvirenti, L., and Fierli, F.: Comparison of various linear depolarization parameters measured by lidar, Appl. Opt., 38, 4425-4432, 1999.

Carslaw, K. S., Wirth, M., Tsias, A., Luo, B. P., Dörnbrack, A., Leutbecher, M., Volkert, H., Renger, W., Bacmeister, J. T., and Peter, T.: Particle microphysics and chemistry in remotely observed mountain polar stratospheric clouds, J. Geophys. Res., 103(D5), 5785-5796, 1998.

Dhaniyala, S., McKinney, K., and Wennberg, P.: Lee-wave clouds and denitrification of the polar stratosphere, Geophys. Res. Lett., 9, 1322, doi:10.1029/2001GL013900, 2002.

Dörnbrack, A. and M. Leutbecher: Relevance of mountain waves for the formation of polar stratospheric clouds over Scandivania: A 20 year climatology, J. Geophys. Res., 106(D2), 1583-1593, 2001.

Dörnbrack, A., Birner, T., Fix, A., Flentje, H., Meister, A., Schmid, H., Browell, E. V., and Mahoney, M. J.: Evidence for inertia gravity waves forming polar stratospheric clouds over Scandinavia, J. Geophys. Res., 107(D20), 8287-8304, doi:10.1029/2001JD000452, 2002. 
di Sarra, A., Cacciani, M., Fiocco, G., Fuà, D., and Jørgensen, T. S.: Lidar observations of polar stratospheric clouds over northern Greenland in the period 1990-1997, J. Geophys. Res., 107(D12), 4152-4167, doi:10.1029/2001JD001074, 2002.

Fromm, M. D., Alfred, J. M.., and Pitts, M.: A unified longterm, high-latitude stratospheric aerosol and cloud database using SAM II, SAGE II, and POAM II/III data: Algorithm description, database definition and climatology, J. Geophys. Res., 108, D12, 4366-4382, doi:10.1029/2002JD002772, 2003.

Fueglistaler, S., Luo, B. P., Buss, S., Wernli, H., Voigt, C., Müller, M., Neuber, R., Hostetler, C. A., Poole, L. R., Flentje, H., Fahey, D. W.,Northway, M. J., and Peter, Th.: Large NAT particle formation by mother clouds: Analysis of SOLVE/THESEO-2000 observations, Geophys. Res. Lett., 29, 1610, doi:10.1029/2001GL014548, 2002.

Fueglistaler, S., Buss, S., Luo, B. P., Wernli, H., Flentje, H., Hostetler, C. A., Poole, L. R., Carslaw, K. S., and Peter, Th.: Detailed modeling of mountain wave PSCs, Atmos. Chem. Phys., 3, 697-712, doi:10.5194/acp-3-697-2003, 2003.

Hansen, D. R. and Mauersberger, K.: Laboratory studies of the nitric acid trihydrate: Implications for the south polar stratosphere, Geophys. Res. Lett., 15, 855-858, 1988.

Höpfner, M., Luo, B. P., Massoli, P., Cairo, F., Spang, R., Snels, M., Di Donfrancesco, G., Stiller, G., von Clarmann, T., Fischer, H., and Biermann, U.: Spectroscopic evidence for NAT, STS, and ice in MIPAS infrared limb emission measurements of polar stratospheric clouds, Atmos. Chem. Phys., 6, 1201-1219, doi:10.5194/acp-6-1201-2006, 2006.

Höpfner, M., Pitts, M. C., and Poole, L. R.: Comparison between CALIPSO and MIPAS observations of polar stratospheric clouds, J. Geophys. Res., 114, D00H05, doi:10.1029/2009JD012114, 2009.

Hunt, W. H, Winker, D. M., Vaughan, M. A., Powell, K. A., Lucker, P. L., and Weimer, C.: CALIPSO Lidar Description and Performance Assessment, J. Atmos. Oceanic Technol., 26, 1214-1228, doi:10.1175/2009JTECHA1223.1, 2009.

Kalnay, E., Kanamitsu, M., Kistler, R., Collins, W., Deaven, D., Gandin, L., Iredell, M., Saha, S., White, G., Woollen, J., Zhu, Y., Leetmaa, A., Reynolds, R., Chelliah, M., Ebisuzaki, W., Higgins, W., Janowiak, J., Mo, K. C., Ropelewski, C., Wang, J., Jenne, R., and Joseph, D.: The NCEP/NCAR 40-year reanalysis project, Bull. Amer. Meteor. Soc., 77, 437-470, 1996.

List, R. J.: Smithsonian Meteorological Tables, 6th edition, Smithsonian Institution Press, Washington, DC, 527 pp., 1984.

Liu, Z., Vaughan, M. A., Winker, D. M., Hostetler, C. A., Poole, L. R., Hlavka, D., Hart, W., and McGill, M.: Use of probability distribution functions for discriminating between cloud and aerosol in lidar backscatter data, J. Geophys. Res., 109, D15202, doi:10.1029/2004JD004732, 2004.

Lowe, D. and MacKenzie, A. R.: Polar stratospheric cloud microphysics and chemistry, J. Atmos. Solar-Terr. Phys., 70, 13-40, 2008.

Mann, G. W., Carslaw, K. S., Chipperfield, M. P., and Davies, S.: Large nitric acid trihydrate particles and denitrification caused by mountain waves in the Arctic stratosphere, J. Geophys. Res., 110, D08202, doi:10.1029/2004JD005271, 2005.

Massoli, P., Maturilli, M., and Neuber, R.: Climatology of Arctic polar stratospheric clouds as measured by lidar in Ny-Ålesund, Spitsbergen $\left(79^{\circ} \mathrm{N}, 12^{\circ} \mathrm{E}\right)$, J. Geophys. Res., 111, D09206,
doi:10.1029/2005JD005840, 2006.

Maturilli, M. and Dörnbrack, A.: Polar stratospheric ice cloud above Spitsbergen, J. Geophys. Res., 111, D18210, doi:10.1029/2005JD006967, 2006.

Müller, M., Neuber, R., and Beyerle, G.: Non-uniform PSC occurrence within the Arctic polar vortex, Geophys. Res. Lett., 28, 4175-4178, 2001.

Pagan, K. L., Tabazadeh, A., Drdla, K., Hervig, M. E., Eckermann, S. D., Browell, E. V., Legg, M. J., and Foschi, P. G.: Observational evidence against mountain-wave generation of ice nuclei as a prerequisite for the formation of three solid nitric acid polar stratospheric clouds observed in the Arctic in early December 1999, J. Geophys. Res., 109, D04312, doi:10.1029/2003JD003846, 2004.

Pawson, S. and Naujokat, B.: The cold winters of the middle 1990s in the northern lower stratosphere, J. Geophys. Res., 104, 1420914222, 1999.

Pawson, S., Naujokat, B., and Labitzke, K.: On the polar stratospheric cloud formation potential on the northern stratosphere, J. Geophys. Res., 100, D11, 23215-23225, 1995.

Pitts, M. C., Thomason, L. W., Poole, L. R., and Winker, D. M.: Characterization of Polar Stratospheric Clouds with spaceborne lidar: CALIPSO and the 2006 Antarctic season, Atmos. Chem. Phys., 7, 5207-5228, doi:10.5194/acp-7-5207-2007, 2007.

Pitts, M. C., Poole, L. R., and Thomason, L. W.: CALIPSO polar stratospheric cloud observations: second-generation detection algorithm and composition discrimination, Atmos. Chem. Phys., 9, 7577-7589, doi:10.5194/acp-9-7577-2009, 2009.

Plougonven, R., Teitelbaum, H., and Zeitlin, V.: Inertia gravity wave generation by the tropospheric midlatitude jet as given by the Fronts and Atlantic Storm-Track Experiment radio soundings, J. Geophys. Res., 108, D21, 4686-4703, doi:10.1029/2003JD003535, 2003.

Poole, L. R. and Pitts, M. C.: Polar stratospheric cloud climatology based on Stratospheric Aerosol Measurement II observations from 1978 to 1989, J. Geophys. Res., 99, 13083-13089, 1994.

Powell, K. A., Hostetler, C. A., Liu, Z., Vaughan, M. A., Kuehn, R. E., Hunt, W. H., Lee, K., Trepte, C. R., Rogers, R. R., Young, S. A., and Winker, D. M.: CALIPSO Lidar Calibration Algorithms: Part I - Nighttime $532 \mathrm{~nm}$ Parallel Channel and $532 \mathrm{~nm}$ Perpendicular Channel, J. Atmos. Oceanic Technol., 26, 2015-2033, doi:10.1175/2009JTECHA1242.1, 2009.

Reichardt, J., Dörnbrack, A., Reichardt, S., Yang, P., and McGee, T. J.: Mountain wave PSC dynamics and microphysics from ground-based lidar measurements and meteorological modeling, Atmos. Chem. Phys., 4, 1149-1165, doi:10.5194/acp-4-11492004, 2004.

Stephens, G. L. , Vane, D. G., Boain, R. J., Mace, G. G., Sassen, K., Wang, Z., Illingworth, A. J., O'Connor, E. J., Rossow, W. B., Durden, S. L., Miller, S. D., Austin, R. T., Benedetti, A., Mitrescu, C., and the CloudSat Science Team: The CloudSat mission and the A-Train: A new dimension of space-based observations of clouds and precipitation, Bull. Am. Meteorol. Soc., 83, 1771-1790, 2002.

Stefanutti, L, Sokolov, L., Balestri, S., MacKenzie, A. R., and Khattatov, V.: The M-55 Geophysica as a platform for the airborne polar experiment, J. Atmos. Ocean. Tech., 16, 1303-1312, 1999.

Tsias, A. , Wirth, M., Carslaw, K. S., Biele, J., Mehrtens, H., Reichardt, J., Wedekind, C., Weiß, V., Renger, W., Neuber, R., 
von Zahn, U., Stein, B., Santacesaria, V., Stefanutti, L., Fierli, R., Bacmeister, J., and Peter, T.: Aircraft lidar observations of an enhanced type Ia polar stratospheric clouds during APEPOLECAT, J. Geophys. Res., 104, D19, 23961-23969, 1999.

Voigt, C., Larsen, N., Deshler, T., Kröger, C., Schreiner, J., Mauersberger, K., Luo, B., Adriani, A., Cairo, F., Di Donfrancesco, G., Ovarlez, J., Ovarlez,H., Dörnbrack, A., Knudsen, B., and Rosen, J.: In situ mountain-wave polar stratospheric cloud measurements: Implications for nitric acid trihydrate formation, J. Geophys. Res., 108, 8331, doi:10.1029/2001JD001185, 2003.

Voigt, C., Schlager, H., Luo, B. P., Dörnbrack, A., Roiger, A., Stock, P., Curtius, J., Vössing, H., Borrmann, S., Davies, S., Konopka, P., Schiller, C., Shur, G., and Peter, T.: Nitric Acid Trihydrate (NAT) formation at low NAT supersaturation in Polar Stratospheric Clouds (PSCs), Atmos. Chem. Phys., 5, 13711380, doi:10.5194/acp-5-1371-2005, 2005. von Hobe, M., Grooß, J.-U., Pope, F., Peter, T., Cairo, F., Orsolini, I., Volk, C. M., Marchand, M., Janosi, I. M., Schlager, H., Stroh, F., Rex, M., Wienhold, F.: Reconciliation of essential process parameters for an enhanced predictability of arctic stratospheric ozone loss and its climate interactions, to be submitted to Atmos. Chem. Phys., 2011.

Winker, D. M., McGill, M., and Hunt, W. H.: Initial performance assessment of CALIOP, Geophys. Res. Lett., 34, L19803, doi:10.1029/2007GL030135, 2007.

Winker, D. M., Vaughan, M. A., Omar, A. H., Hu, Y., Powell, K. A., Liu, Z., Hunt, W. H., and Young, S. A.: Overview of the CALIPSO Mission and CALIOP Data Processing Algorithms, J. Atmos. Oceanic Technol., 26, 2310-2323, doi:10.1175/2009JTECHA1281.1, 2009.

WMO (World Meteorological Organization), Scientific Assessment of Ozone Depletion: 2006, Global Ozone Research and Monitoring Project-Report No. 50, Geneva, Switzerland, 2007. 